\title{
Compressive Strength of Structural Lightweight Concrete Using Styrofoam as an Aggregate Substitution
}

\author{
Sumarno Agung dan Abiyyah Rifdah \\ Fakultas Teknik, Universitas Mercu Buana, Indonesia, \\ Agung.sumarno@lipi.go.id, Rif.aby27@gmail.com
}

\begin{abstract}
Concrete is one of the important components making up the construction structure. In its development, innovations in the manufacture of concrete both in mixed materials and concrete working methods continue to develop. Lightweight concrete with a mixture of Styrofoam as an aggregate substitution is one of the innovations made as an alternative to natural aggregate which cannot be renewed and can be used up at any time. This study aims to determine the effect of the addition of styrofoam as an aggregate substitution on workability, density, absorption and compressive strength of concrete. The method used in this study is an experimental method of structural lightweight concrete using styrofoam as a substitution of coarse and fine aggregates. Data obtained from testing directly in the laboratory. The variations in the use of Styrofoam as a gross aggregate substitution of $0 \%, 50 \%, 100 \%$ then continued with $25 \%$ and $50 \%$ fine aggregate substitution, for the results of density, absorption and compressive strength, respectively decreased as the volume of aggregate substitution increased.
\end{abstract}

\section{Keywords}

Styrofoam, lightweight concrete, density, absorption, compressive strength

\section{Introduction}

Infrastructure development and office areas in Indonesian now increasing which is nothing but to fulfill of facilities and infrastructure needs for supporting public activities, the construction in general cannot be separated from the use of concrete, use of aggregates as a concrete mixture has a greater presentation compared to other materials that is $60 \%-75 \%$ concrete filler material (Portland Cemen Assosiation). In accordance SNI, raw materials is the natural resources that can not be renewed, in use of excess and uncontrolled Is as one of the worlds largest damage. Therefore, it needs an effort to minimize the impact of damage inflicted and need to consider the use of concrete building materials that are made with the concept of friendly environment or other alternative as an environmentally friendly substitute.

One of the innovations in making concrete is use a styrofoam as a concrete mixture for aggregates substitution and can be categorized as environmentally friendly concrete because according to The Institution of Structural Engineers / ISE, 1999 in Ahmad Basuki 2012, making environmentally friendly concrete can be done by realizing 4 (four) environmental sustainability and conservation efforts, that is: (1) Reduction of greenhouse gas emissions ( tha largest co2 ), (2) energy efficiency and basic materials, (3) use of waste material, and (4) reduction of health / safety disrupt effects on construction users, both arising during the construction process or arising during building operations, by using the 4R concept (Reduce, Refurbish, Reuse and Recycle). 

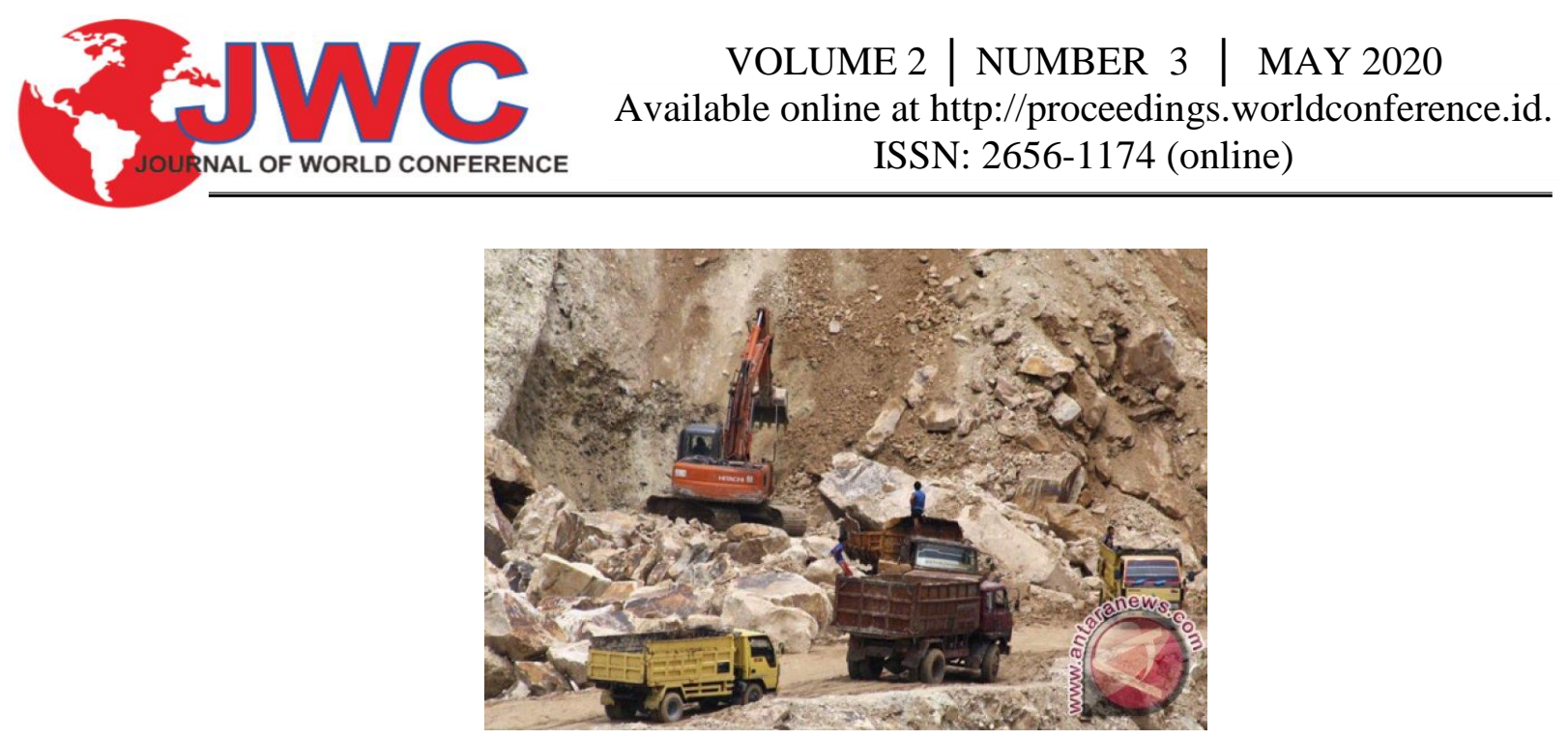

Figure 1. Exploitation Of Natural Resources

Source : www.antaranews.com

Aside from being an alternative to aggregate substitution, the use of Styrofoam can reduce the residual waste of household needs because styrofoam is plastic number 6 in the plastic classification, namely polystyrene. Styrofoam is one of the preparations of polystyrene which is a formation of styrene compounds that use benzene in its processing. Styrofoam waste is classified as inorganic waste which difficult to decompose so that it is bad for health and has the potential to damage the environment, if allowed to pile up just like that and improper use styrofoam can be very dangerous [Michelli,2017].

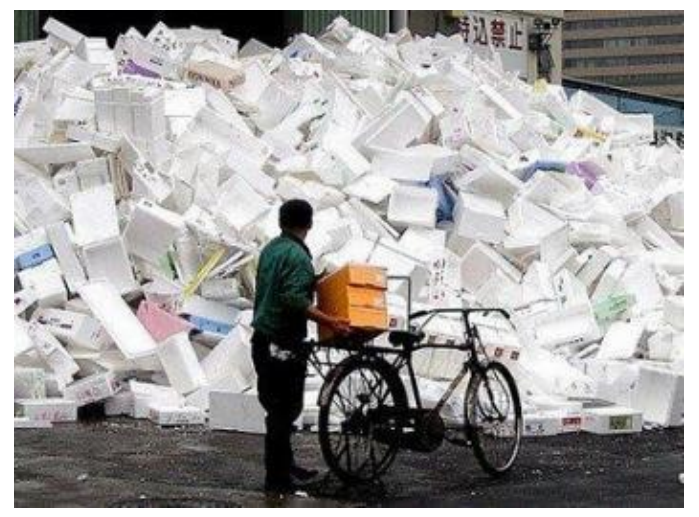

Figure 2. Styrofoam Waste

\section{Source : Google}

This research is expected to be able to add information about the effect of aggregate substitution with styrofoam in structural lightweight concrete on compressive strength of concrete and can reduce environmental damage by reducing the use of aggregates and the use of styrofoam waste as a substitute.

\subsection{Problem Formulation}

Based on the background stated earlier, the main issues in the study are:

a. What is the effect of using styrofoam as an aggregate substitution on concrete workability?

b. What is the effect of using styrofoam as an aggregate substitution on concrete density?

c. What is the effect of using styrofoam as an aggregate substitution on the absorption of concrete water?

d. What is the effect of using styrofoam as an aggregate substitution on the compressive strength value of concrete? 


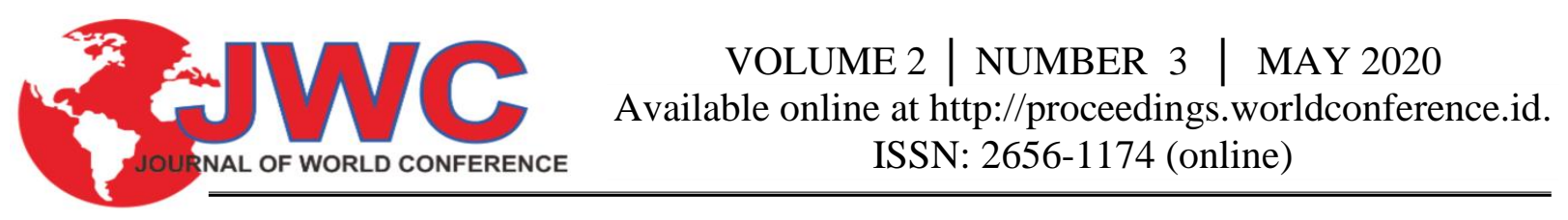

\subsection{Research Purposes}

The purpose of this research is:

a. Determine the effect of using styrofoam as an aggregate substitution on the workability of the concrete mixture.

b. Knowing the effect of using styrofoam as an aggregate substitution on the density of concrete.

c. Knowing the effect of using styrofoam as an aggregate substitution on concrete absorption.

d. Knowing the effect of using styrofoam as an aggregate substitution on the compressive strength value of concrete.

\section{Methodology}

The method used in this study is an experimental method of structural lightweight concrete using styrofoam as a substitution of coarse and fine aggregates. Data obtained from testing directly in the laboratory, The test conducted is testing the concrete workability, concrete density, concrete water absorption and concrete compressive strength. All testing processes and procedures refer to the SNI (Indonesian National Standard) and ASTM (American Society for Testing and Material) methods. Data from the test results on lightweight concrete mechanics are then calculated to get an average value. The value of the compressive strength of experimental concrete with a volume of $0 \%, 50 \%, 100 \%$ of coarse aggregate substitution and then followed by $25 \%$ and $50 \%$ of fine aggregate substitution then compared with the value of structural concrete compressive strength as a control.

Figure 3. Research Methodology
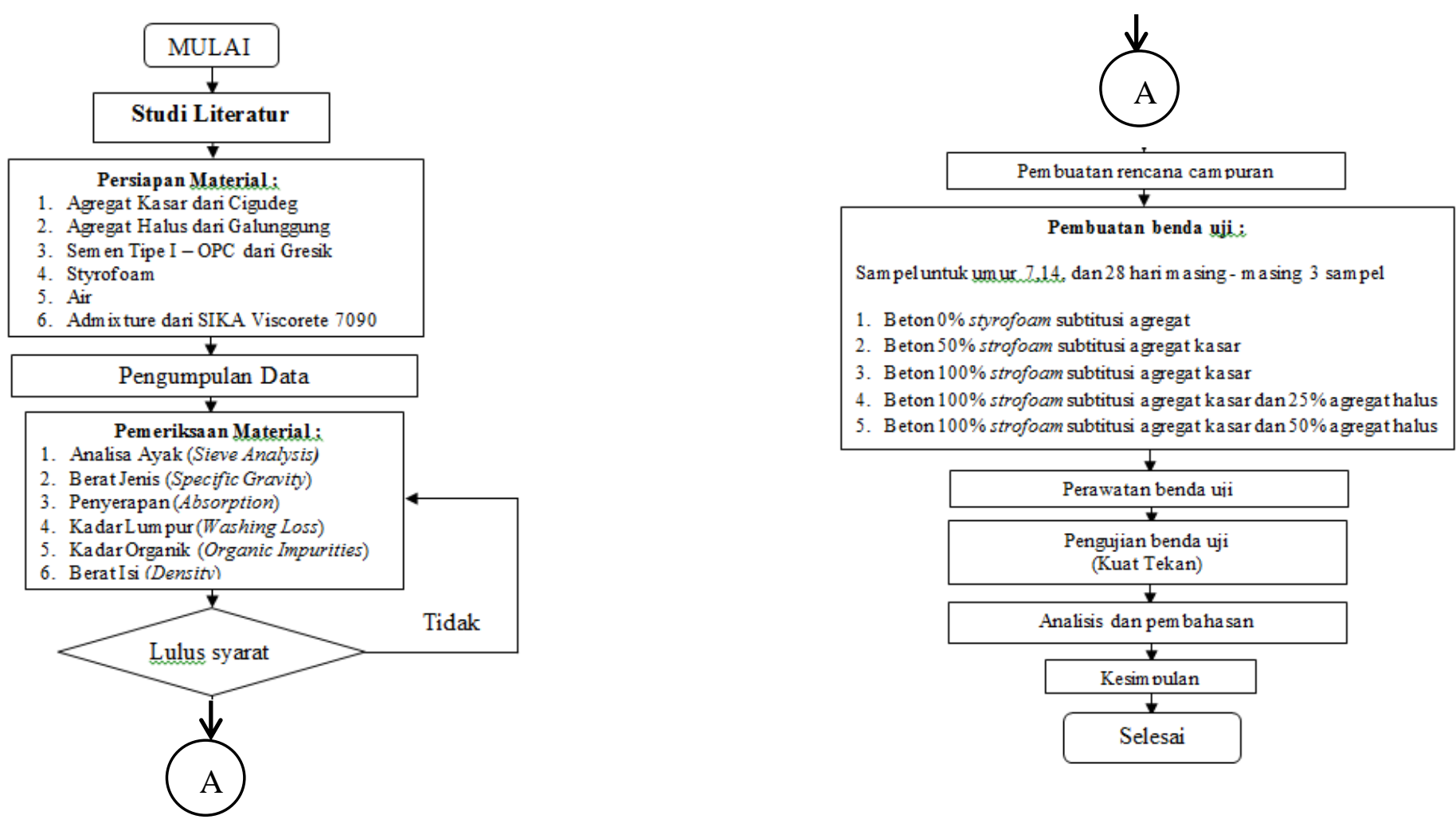

The research method used was an experimental laboratory method in the Concrete Laboratory of PT. Wika Beton is located in the District of Cileungsi by making normal quality concrete and adding styrofoam levels of $0 \%$, $50 \%, 100 \%$ of the volume of coarse aggregate then followed by $25 \%$ and $50 \%$ substitution of fine aggregate. In the initial planning, the quality of concrete used was K-600. Concrete cylindrical specimens with a diameter of $10 \mathrm{~cm}$ 
and height of $20 \mathrm{~cm}$. Concrete compressive strength test is done after the test specimen is 7, 14 and 28 days with repeated compressive loading.

\section{Result}

a. Agregates

The specification of aggregates are based on the test results in the following table:

Table 1. Aggregates testing

\begin{tabular}{lcc}
\hline Type Of Testing & Coarse Aggregate & Fine Aggregate \\
\hline Finess Modulus (FM) & 2,615 & 6,937 \\
Specific Gravity & 2,552 & 2,536 \\
Absorption & $1,410 \%$ & $4,058 \%$ \\
Content Weight & 1,513 & 1,542 \\
Sludge Level & $0,7 \%$ & $1,05 \%$ \\
Organic Impurities & NO.2 & - \\
\hline
\end{tabular}

Source: Data in research, 2019

b. Concrete Mix Design

The specification of mix design are based on the test results in the following table:

Table 2. Mix Design

\begin{tabular}{ccccccc}
\hline Material & Satuan & K1 & K2 & K3 & K4 & K5 \\
\hline Semen & $\mathrm{Kg}$ & 478 & 478 & 478 & 478 & 478 \\
Split & $\mathrm{Kg}$ & 994 & 497 & - & - & - \\
Styrofoam & $\mathrm{Kg}$ & - & 2,92 & 5,84 & 6.95 & 8,06 \\
Pasir & $\mathrm{Kg}$ & 750 & 750 & 750 & 562,5 & 375 \\
Adm & Liter & 5,26 & 5,26 & 5,26 & 5,26 & 5,26 \\
Air & Liter & 153 & 153 & 153 & 153 & 153 \\
\hline
\end{tabular}

Source: Data in research, 2019

\section{c. Workability}

Testing concrete slump using slump flow testing, results can be seen in the following table: 
Tabel 3. Slump Flow

\begin{tabular}{cc}
\hline Mix Variation & Slum Flow \\
\hline Kontrol & 58 \\
$50 \%$ & 63 \\
$100 \%$ & 62,5 \\
$100 \%+25 \%$ & 62 \\
$100 \%+50 \%$ & 52 \\
\hline
\end{tabular}

Source: Data in research, 2019

\section{d. Concrete Density}

Concrete density are based on the test results in the following graphic and table:

Figure 4. Concrete Density

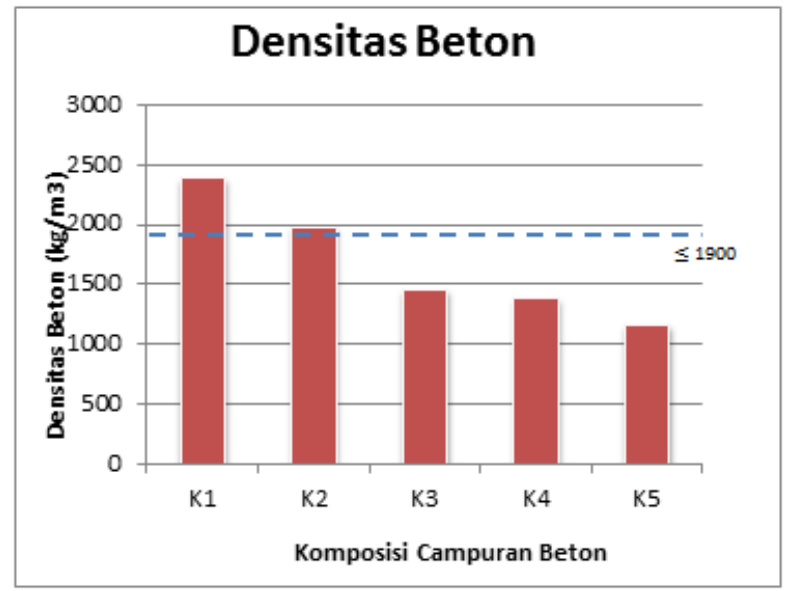

Source: Data in research, 2019

Tabel 4. Concrete Density

\begin{tabular}{cc}
\hline Mixed Variations & Density \\
\hline Kontrol & 2385 \\
$50 \%$ & 1974,52 \\
$100 \%$ & 1450,11 \\
$100 \%+25 \%$ & 1375,79 \\
$100 \%+50 \%$ & 1154,99 \\
\hline
\end{tabular}

Source: Data in research, 2019

\section{e. Concrete Absorption}

The results of the absorption of water in concrete in the following graphic and table: 


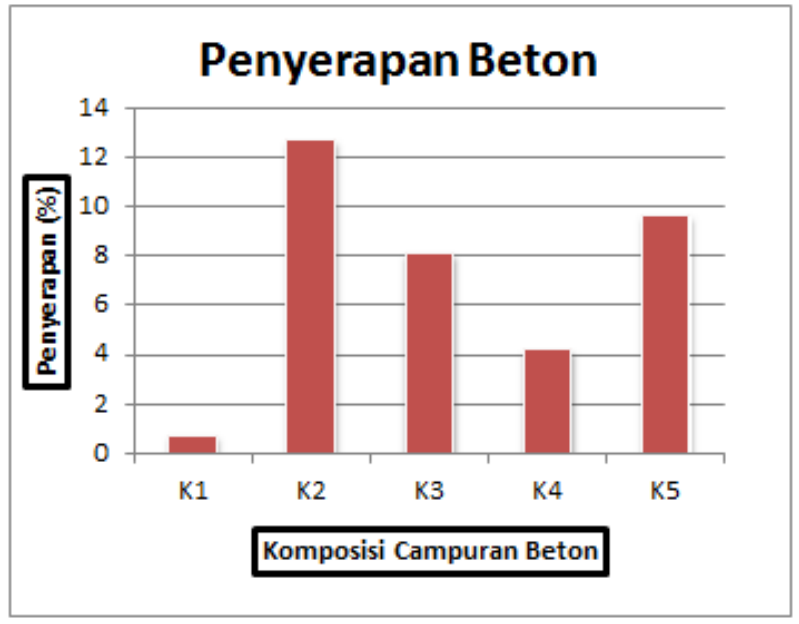

Source: Data in research, 2019

Figure 4. Concrete Absorption

Tabel 5. Concrete Density

\begin{tabular}{cc}
\hline Mixed Variations & Absorption( \%) \\
\hline Kontrol & $0,69 \%$ \\
$50 \%$ & 12,66 \\
$100 \%$ & 8,07 \\
$100 \%+25 \%$ & 4,16 \\
$100 \%+50 \%$ & 9,62 \\
\hline \multicolumn{2}{c}{ Source: Data in research, 2019}
\end{tabular}

\section{f. Compressive Strength}

Concrete compressive strength testing is done by using a compressive test tool with 9 concrete samples per variation, 3 samples on days 7, 14 other samples on day 28. Following are the results of the 7-day-old concrete compressive strength test:

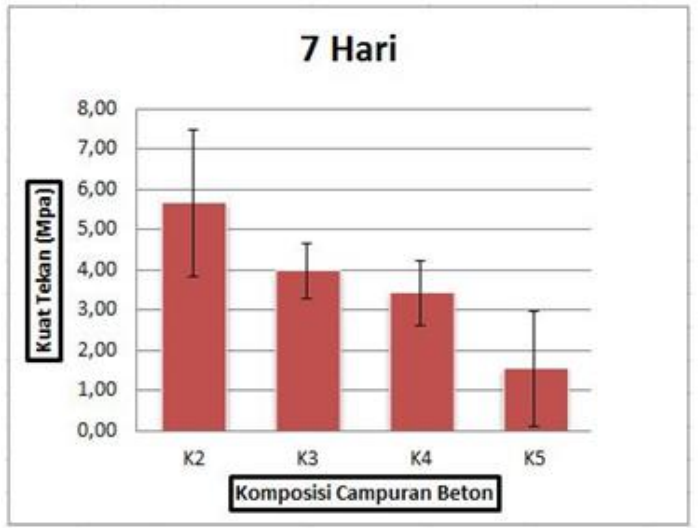

Source: Data in research, 2019

Figure 5. Concrete Compressive Strength day 7 
Table 6. Concrete Compressive Strength day 7

\begin{tabular}{cc}
\hline Mixed Variations & Compressive Strength (Mpa) \\
\hline Kontrol & 42,7 \\
$50 \%$ & 5,66 \\
$100 \%$ & 3,97 \\
$100 \%+25 \%$ & 3,42 \\
$100 \%+50 \%$ & 1,54 \\
\hline
\end{tabular}

Source: Data in research, 2019

Following are the results of the 14-day-old concrete compressive strength test:

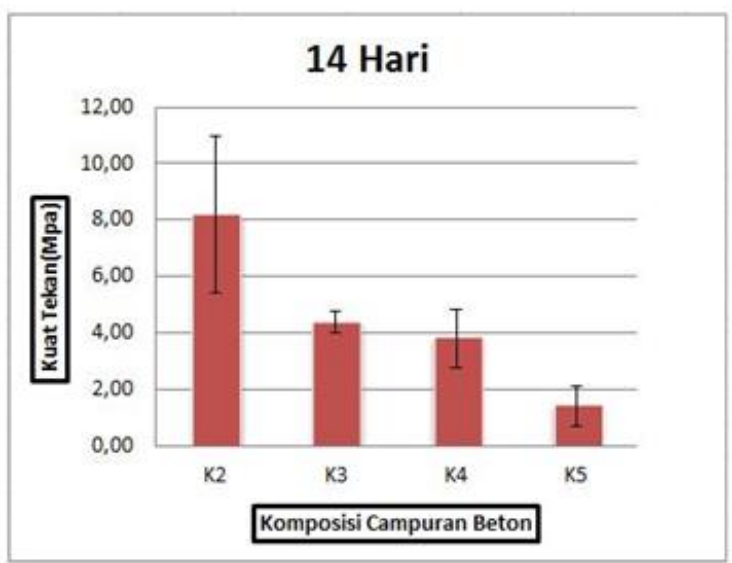

Source: Data in research, 2019

Figure 6. Concrete Compressive Strength day 14

Table 7. Concrete Compressive Strength day 14

\begin{tabular}{cc}
\hline Mixed Variations & Compressive Strength (Mpa) \\
\hline Kontrol & 45,99 \\
$50 \%$ & 8,21 \\
$100 \%$ & 4,04 \\
$100 \%+25 \%$ & 3,82 \\
$100 \%+50 \%$ & 1,43 \\
\hline & Source: Data in research, 2019
\end{tabular}

Following are the results of the 28-day-old concrete compressive strength test: 


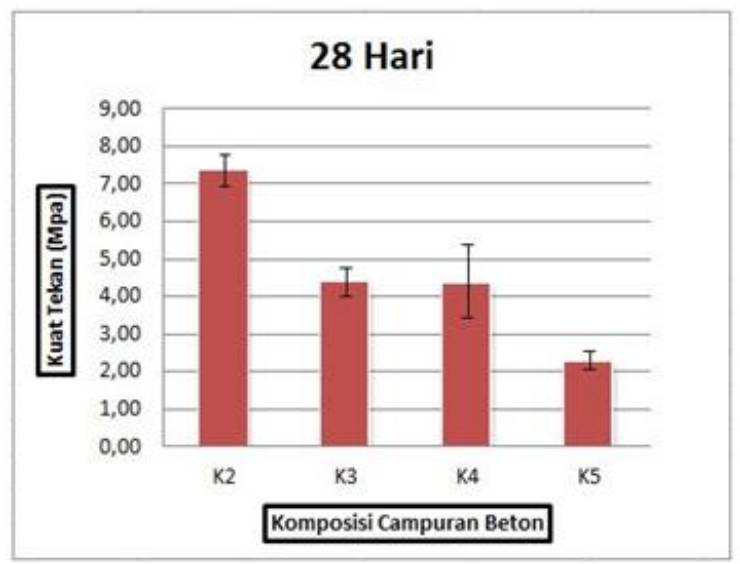

Source: Data in research, 2019

Figure 7. Concrete Compressive Strength day 28

Table 8. Concrete Compressive Strength day 28

\begin{tabular}{cc}
\hline Mixed Variations & Compressive Strength (Mpa) \\
\hline Kontrol & 55,79 \\
$50 \%$ & 7,36 \\
$100 \%$ & 4,39 \\
$100 \%+25 \%$ & 4,38 \\
$100 \%+50 \%$ & 2,28 \\
\hline
\end{tabular}

Source: Data in research, 2019

\section{Conclussion}

From the results of tests that have been carried out as a whole to the study of the use of styrofoam as an aggregate substitution in the concrete mix can be concluded as follows:

1. The use of styrofoam as an aggregate substitution does not greatly affect the value of the concrete slump. Thus, the level of workmanship is almost the same as that of control concrete.

2. There is a decrease in the value of concrete density with increasing volume of aggregate substitution with styrofoam from control concrete to K5 concrete and from these results meet the planned density value for lightweight concrete in accordance with SNI 03-2847-2002.

3. Absorption of concrete water with the highest value is in a mixture of $50 \%$ mixture of coarse aggregate substitution with styrofoam.

4. Concrete compressive strength decreases with increasing volume of aggregate substitution with styrofoam and does not achieve the compressive strength of plans for structural concrete.

5. Overall the variation of concrete mix results the highest compressive strength of concrete at the age of 14 days for a concrete mixture variation of $50 \%$ substitution of coarse aggregate with styrofoam.

\section{Recommendation}

Research conducted, there are several suggestions that can be considered for further research, that:

1. The use of styrofoam as an aggregate substitution produces a low concrete compressive strength value. Therefore, it is recommended in its use as concrete for non-structural parts such as pavement floors and nonload bearing walls. 
2. Styrofoam is given a coating which is able to attach Styrofoam with other materials because during the stirring process of Styrofoam it is not easily mixed and not spread evenly, according to Dedi Endi's research in the Inovtek Journal vol.6 no.2 p.110, October 2016 Styrofoam coating can increase the compressive strength of concrete.

\section{References}

www.antaranews.com

www.Google.com 